\title{
Comparative Studies of Physiochemical and Microbial Analysis of Commercial Pure Water and Their Sources
}

\author{
Ajetunmobi Asibiallau Oladipupo \\ Lagos State Polytechnic, School Of Technology
}

\begin{abstract}
Water is an important and a life-sustaining compound that every living thing (plant and animal) cannot do without. It is the driving force behind all metabolic activities in our bodies. In respective of the method of treatment and purification of drinking water, the standard for safety must not be compromised.

Human beings make use of water in almost all areas of their lives. As a matter of fact, man's body is said to contain about $57 \%$ of water. Entailed in this write up were the physiochemical and microbial analysis of commercial pure water samples and their sources produced in different parts of Ikorodu, Lagos.
\end{abstract}

Key words: $W S=$ Water Sachet, UDW = Underground Water Sample, D.O = Dissolve Oxygen

\section{Introduction}

Some substances are present in water that makes it a universal solvent and helps to function very well. Substances present in the water that make it essential are Chlorine, Calcium and Magnesium e.t.c. but excess of this causes harm in the usage. There are also some micro-organisms present in water that can cause diseases in animals e.g. Escherichia coli (E.coli) and faecal streptococci (Bibek Ray And Arum Bhunia $4^{\text {th }}$ Edition)

Water is the most common solvent in nature. It is usually referred to as the universal solvent because it dissolves a greater variety of substances than any other liquid or solvent. Water molecules has a structure which is polar in nature i.e. one size of the molecule is positively charge while the other size is negatively charged. As a result of this structure, water is an excellent solvent for electrovalent solutes such as mineral salts, mineral acids and bases. These are mainly inorganic substances. All covalent compounds which contain the hydroxyl group will also dissolve easily in water. Examples are organic solid like sugar and organic liquid like alkanol and propane 1, 2, 3-triol (glycerol). Besides these, all gases can dissolve in water to some extent.

Gases which ionize in solution, or which react with water are found to be very soluble e.g. ammonia, hydrogen chloride and nitrogen (iv) oxide. Other gases like sulphur (iv) oxide, carbon (iv) oxide and chlorine, which ionize slightly are found to be fairly soluble in water. Gases which do not ionize at all in water are only sparingly soluble. Examples of such gases are oxygen, hydrogen, nitrogen and carbon (iv) oxide. In general, the solubility of gases decreases with an increase in the temperature. Water and other polar solvent dissolve most organic substance, but only a few organic ones. Organic substances dissolve readily in solvents like kerosene, petrol, benzene and turpentine.

Water is a common chemical substance that is essential for the survival of all known form of life. There are so many names given to water in accordance with its various forms.

\section{Objective}

This is to determine if there are still some micro-organism present in the samples of water consumed by people, which must have being tested or analyzed by the producers of the samples of the water before distribution.

Explosion of a hydrogen and oxygen gas mixture yield water vapor (Priestley 1781). The ratio by volume of hydrogen to oxygen in that reaction at constant temperature and pressure was 2:1 (Cavendish).

Water is a common chemical substance that is essential for the survival of all known forms of life (Wikipedia, the free encyclopedia)

In typical usage, water refers only to its liquid form state, but the substances also have a solid state, ice and a gaseous state. It is the three quarter of the earth and one of the common substances knows.

Another definition is "water is the chemical substance with a chemical formula $\mathrm{H}_{2} \mathrm{O}$ that is one molecule of water has two hydrogen atom covalently boded to a single oxygen atom: (Osei Yaw Ababio)

$2 \mathrm{H}_{2(\mathrm{~g})}+\mathrm{O}_{2(\mathrm{~g})} \longrightarrow 2 \mathrm{H}_{2} \mathrm{O}_{(\mathrm{g})}$

Co-ordinate covalent bond of water is<smiles>O</smiles> 


\section{Physical Properties}

It is a tasteless and odorless liquid at ambient temperature and pressure.

The colour of water and ice is intrinsically, a very light blue hue, although water appears in small quantities. Water is transparent and thus, aquatic plants can live within it because sunlight can reach them. Only strong ultra-violet light is slightly absorbed in it.

The boiling point of water and all other liquid is directly related to the barometric pressure. For example, on the top of mount Everest, water boils at about $68^{\circ} \mathrm{c}\left(154^{\circ} \mathrm{F}\right)$ compared to $100^{\circ} \mathrm{C}\left(212^{\circ} \mathrm{F}\right)$ at sea level. Conversely, water deep in the ocean near geothermal vents can reach temperature of hundred of degrees.

\section{Chemical Properties}

Water has a high surface tension caused by the weak interaction (Van Der Waal force) between water molecules because it is polar. The apparent elasticity by surface tension drives the capillary waves. (Wikipedia) It has high adhesion properties because of its polar nature.

Capillary action refers to the tendency of water to move up a narrow tube against the force of gravity. These properties are relied upon by all vascular plants such as trees. Pure water has a low electrical conductivity, but this increases significantly upon salvation of a small amount of ionic, material such as sodium chloride $\mathrm{NaCl}$ ). It has the second highest specific heat capacity of any known chemical compound after ammonia $\left(\mathrm{NH}_{3}\right)$, as well as a high heat of vaporization $(4065 \mathrm{KJmol} / \mathrm{l})$, both of which are a result of the existence hydrogen bonding between its molecules. These two unusual properties allow water to moderate earth's climates by buffering large fluctuations in temperature. (Wikipedia)

The maximum density of water is at $3.98^{\circ} \mathrm{C}\left(39.96^{\circ} \mathrm{F}\right)$. It becomes less dense upon freezing expanding $9 \%$, this cause an unusual phenomenon. The floats of water, and water organisms can live inside a partly frozen pond because the water on the bottom has a temperature of around $4^{0} \mathrm{C}\left(39^{\circ} \mathrm{F}\right)$.

Water form a zoetrope with many other solvents

It can be splitted by electrolysis into hydrogen and oxygen.

\section{Types Of Water}

Water is one of the most common substances known. It is a good solvent for many substances and rarely occurs in its pure form in nature.

\section{Natural Water}

Natural water includes rainfall, spring water, lake water, well water and sea water. Rain water is the purest form of natural water because it is formed as a result of the condensation of water vapour in the atmosphere i.e. it is a natural form of distilled water. Spring water contains a considerable amount of mineral salt, but very little suspended impurities such as dust and bacteria, so it is a good source of drinking, if it is sited away from source of underground pollution such as pit latrine, lined with brich and covered. Water from deep wells tends to be less polluted than that from surface wells.

Generally, it is safer to boil well water before drinking. River water, lake water and sea water contain a lot of dissolved air, mineral salts, bacterial and organic remains. These waters have to be specially purifies before they can be used for drinking. All the types of natural water are in constant, forming a gigantic water cycle.

\section{Treated Water}

Treated water is usually prepared for special purpose. Examples of treated water are distilled water, pipe borne water and chlorinated water use in swimming pools.

\section{Distilled Water}

Distilled water is chemically pure water. It is prepared by condensing steam or using clear vessels. Water prepared using exchange resin is called deionized water.

Distilled water is used in the laboratory for preparing reagents, in industry, for preparation of drugs and car batteries.

\section{Water Pollution}

Pollution means to make pond or water unclean (American college dictionary).

Water pollution occurs when a body of water is adversely affected due to the addition of large amount of materials to the water. When the water is unfit for its intended use, water is considered polluted.

\section{Types Of Water Pollution}

There are point sources and non-point sources. Point sources of pollution occur when harmful substances are emitted directly into a body of water. 
A non-point source delivers pollutant indirectly through environmental changes. (Karen C. Timberlake $10^{\text {th }}$ edition)

\section{Causes Of Pollution}

Many causes of pollution include sewage and fertilizers containing nutrients such as nitrate and phosphates. In excess levels, nutrients over stimulate the growth of these types of organisms consequently clogs our water ways, use up dissolved oxygen as they decompose.

This in turn, proves very harmful to aquatic as it affects the respiration ability of fish and other invertebrates that reside in water. Pollutions also cause silt and other suspended solids such as soil, wash off plowed fields, construct

Ion and loggings sites, urban area and eroded river banks when it rains.

\section{Microorganisms Causing Water Pollution}

Pathogens are another type of pollution that proves harmful. They can cause many illness that range from typhoid minor respiratory and skin diseases. Pathogens include organisms like bacteria, viruses and protozoan. These pollutants enter water ways through untreated sewage, storm rains, septic tanks, runoff from farms and particularly boats that dump sewage. Through microscopically, these pollutants have a tremendous effect evidenced by their ability to cause sickness.

\section{Control Measure Of Water Pollution}

Some methods of controlling water pollution are as follow:

i. Refuse should be buried or properly incinerated with build device to prevent air pollution.

ii. Sewage should be converted to fertilizer.

iii. Safety measures must be implemented to prevent crude oil spill.

iv. Chemical wastes should be converted to harmless biodegradable substances.

v. Strict environmental law should be passed and implemented.

\section{Physical Analysis}

\section{Colour}

Water is colourless, but may also become coloured by industrial wastes, natural iron, manganese and product of corrosion.

\section{Taste and Odour}

The 'taste' and 'odour' are often used loosely and interchangeably. Actually there are forms of tastessour, insipid, salt, sweet and bitter-strictly confirmed in their perception to the taste buds of the tongue. Odours appear to be without limit in number and are known to change in quality as the concentration of the odourous compounds increases. Man senses odours through the olfactory nerves.

\section{PH}

This is used to describe the intensity of acidity of a solution. It is defined as the logarithms of the reciprocal of hydrogen $\left(\mathrm{H}^{+}\right)$concentration expressed in moles per litre. $\mathrm{PH}$ can be measured by using $\mathrm{pH}$ meter with glass electrode and reference electrode immersed in a sample solution. Buffer solution of known PH is used to calibrate the meter (6-8).

\section{Turbidity}

Turbidimeter was used to measure the turbidity of each sample.

\section{Total Suspended Solid}

Spectrophotometer was used in respect of TSS analysis

\section{CHEMICAL ANALYSIS}

This involves chemical reaction and includes; total hardness, chloride, solid test, oxidizable test, phenolphthalein test, total alkalinity test.

\footnotetext{
Alkalinity

Alkalinity is recorded as $\mathrm{mg} / \mathrm{l} \mathrm{CaCO}_{3}$. It's measured by titration using a visual indicator solution or a $\mathrm{PH}$ meter. Alkalinity is determined as the sum of hydroxyl ion and anions of weak acids.
} 


\section{Total Hardness}

Calcium and magnesium ions are the principal hardness forming constituents of water. The presence of calcium and magnesium carbonates and bicarbonates causes carbonate hardness in water. The hardness can be removed easily by boiling. Hardness of water is not harmful for the health of man, on the contrary, calcium promote the removal of cadmium, an element that can adversely affect the cardiovascular system. However, an elevated hardness makes water unsuitable for industrial and domestic purpose. Therefore the standard of total hardness is $7 \mathrm{mg}$-eq/land the maximum permissible value is $(10 \mathrm{mg}-\mathrm{eq} / \mathrm{l})$.

\section{Chloride Test}

Chlorine and its derivative kill bacteria present in water. Chlorine can be added to drinking water to disinfect the water. This is known as chlorination. It also oxidizes the organic substance and for that reason it is a good reagent for preventing the production of microorganism in water. For efficient chlorination, water should intermix with chlorine added and allowed to stay in contact with the reagent for at least 30mins before it will be delivered to consumers. Chlorination water contact can be ensured in pure water tank or in the pipeline which supplies water to consumers, provided that this has a sufficient length. The close of chlorine is determined by a chlorination test so that the water to the consumer has a residual content of non-reacted chlorine between 0.3 and $0.5 \mathrm{mg} / 1(250 \mathrm{mg} / \mathrm{l})$.

\section{Total Acidity}

Acidity is a measure of its capacity to neutralize a base. It is the sum of all titrable acid. It was determined by titration of sodium hydroxide solution with $100 \mathrm{ml}$ of $\mathrm{H}_{2} \mathrm{O}$ sample using two drops of phenolphthalein indicator.

\section{Dissolvedboxygen}

This parameter was measured with a dissolved oxygen meter (DO meter) which gave result of the dissolved oxygen of each of the sample directly.

\section{Nitrate, Sulphates And Phosphate}

In this test there is a specially prepared reagent called pillo. Each test has its own pillo.

\section{Microbial Analysis}

This analysis deals with bacteriology. That is, the coliform counting of bacteria in water. With full knowledge of water analysis, the coliform group of bacteria includes not only organisms originating in the intestinal tract of warm-blooded animals (feacal coli, principally Escherichia coli) but also organism from soil or vegetable (principally Acrobacter aerogenes). Most of these bacteria are pathogens (i.e. diseases causing organism). The principal bacteria water-borne diseases are typhoid fever and cholera.

Parathyroid (salmonellosis) and bacillary dysentery (shigellosis) are groups of water borne disease, but are far less devastating than typhoid fever and cholera. However other categories of parasitic organisms infective to man found in water besides bacteria are; Virus, Worms, Protozoa and Fungi.

\section{Materials And Methodology}

\section{Water Sample}

The table below shows the names of the six commercial pure water samples analyzed with their locations as well as their coded numbers.

\begin{tabular}{|l|l|l|}
\hline Coded Number & Sample Name & Location \\
\hline $\mathrm{WS}_{1}$ & Massah & Garage, Ikorodu \\
\hline $\mathrm{WS}_{2}$ & Koayes & Jokogbola,Ikorodu \\
\hline $\mathrm{WS}_{3}$ & Unipride & $1^{\text {st }}$ Gate, Ikorodu \\
\hline $\mathrm{WS}_{4}$ & Emalyne & $1^{\text {st }}$ Gate, Ikorodu \\
\hline $\mathrm{WS}_{5}$ & Larex & Laspotech Ikorodu \\
\hline $\mathrm{WS}_{6}$ & De-tops & Jumofak, Ikorodu \\
\hline
\end{tabular}

\section{Materials/Apparatus}

$250 \mathrm{~cm}^{3}$ Conical Flask, Burette, $250 \mathrm{~cm}^{3}$ Beaker, Water bath, Weighing balance, Spatula, Volumetric flask, Bunsen burner, Wire gauze, Round bottom flask, Cotton wool, Alluminium foil, Distilled water, Six Petridishes, Autoclave. 
Reagent

Phenolphthalein indicator, 0.02M Hcl, Bromophenol blue, 0.01M Sodium EDTA, Ammonium Chloride, Ammonium hydroxide, $2 \mathrm{M} \mathrm{Hcl}$, Potassium chloride indicator $\left(\mathrm{K}_{2} \mathrm{CrO}_{4}\right), 0.1 \mathrm{M}$ Silver trioxonitrate(v) $\left(\mathrm{AgNO}_{3}\right), 1 \mathrm{M}$ tetraoxosulphate (vi) acid $\left(\mathrm{H}_{2} \mathrm{SO}_{4}\right), 0.02 \mathrm{M}$ Potassium tetraoxomanganete (vii) $\left(\mathrm{KMnO}_{4}\right)$ and $\mathrm{Mac}$ conkey agar.

\section{Physical Analysis}

This was carried out by observing the water samples, but the PH test was carried out using $\mathrm{pH}$ meter.

Colour:- This was carried out by mere viewing the water samples. All the sachet water samples analyzed were found to be colourless. In case of the sources, samples $\mathrm{UD}_{3}$ and $\mathrm{UD}_{6}$ were cloudy probably due to the presence of inorganic contaminants around the sources. Direct consumption of these two sources is not recommended for drinking without proper treatment.

PH:- The Ph value for pure water suppose to be 7.0.

It could be seen that all samples from the source which are all underground had a very high PH values of 4.2, 5.6, 3.8, 3.6, 4.6 and 8.0 respectively which are harmful to health.

\section{Chemical Analysis}

\section{(a) Total Phenolphthalein Alkalinity}

$50 \mathrm{ml}$ of each of the samples were transferred into $250 \mathrm{~cm}^{3}$ of conical flask, six drops of phenolphthalein indicator was added. It gives colourless solutions.

(b) Total Alkalinity

Six drops of bromophenol blue indicator was added to the prepared solution or endpoint in (a) above. It was titrated with 0.02M HCL to form blue-green end point

\section{(c) Total Hardness Test}

$50 \mathrm{~cm}^{3}$ of each of the water samples were pipette into $250 \mathrm{~cm}^{3}$ conical flask. $10 \mathrm{~cm}^{3}$ of buffer solution was added to it, 3 drops of erichrome black T indicator was added and titrated with $0.01 \mathrm{M}$ sodium EDTA, until a clear blue colour was observed.

\section{(d) Solid Test}

$50 \mathrm{ml}$ of each of the samples were evaporated to dryness on a water bath, it was transferred to the oven to constant weight at $100^{\circ} \mathrm{C}$ to $150^{\circ} \mathrm{C}$, and the residue should not be more than $500 \mathrm{mg} / \mathrm{l}$.

(e) Chloride Test

$50 \mathrm{ml}$ of each of the samples were transferred into $250 \mathrm{~cm}^{3}$ of conical flask, $1 \mathrm{ml} \mathrm{K}_{2} \mathrm{CrO}_{4}$ indicator was added, and then titrated with $0.1 \mathrm{M} \mathrm{AgNO}_{3}$ to a pinkish-yellow end point.

(f) Oxidizable Test

$100 \mathrm{ml}$ of each of the samples were transferred into $250 \mathrm{~cm}^{3}$ of conical flask, $10 \mathrm{ml}$ of $1 \mathrm{M} \mathrm{H}_{2} \mathrm{SO}_{4}$ and $1 \mathrm{ml}$ of $0.02 \mathrm{M}$ $\mathrm{KMnO}_{4}$ were added respectively, and boiled for five minutes, until a pink colour was observed.

\section{Microbial Analysis}

$25 \mathrm{~g}$ of Mac conkey agar was weighed and poured into $250 \mathrm{ml}$ of distilled water. The conical flask was placed in an autoclave filled with water to the appropriate level. The pressure value of the autoclave was opened before the autoclave was switched on.

There was a gradual rise in temperature from $(100-121)^{\circ} \mathrm{C}$. The agar was sterilized for $15 \mathrm{~min}$, the autoclave was allowed to cool down to $60^{\circ} \mathrm{C}$ before opening the lid and the agar was brought out.

The Petri dishes were sterilized by passing through the flame before the agar was poured into the six Petridishes, the plates were left to cool and solidify before culturing the different pure water on the agar.

The pure water were cultured by the use of sterilized wire loop, and it streak of the sample were made on the agar.

The agar was placed in the incubator for 24hours. After 24hours, the cultured plates were brought out and check for growth.

Physical Analysis
\begin{tabular}{|l|l|l|l|l|l|l|}
\hline & WS1 & WS2 & WS3 & WS4 & WS5 & WS6 \\
\hline colour & colourless & colourless & colourless & colourless & colourless & colourless \\
\hline PH & 6.88 & 6.50 & 6.40 & 6.80 & 6.87 & 6.30 \\
\hline Odour & Odourless & Odourless & Odourless & Odourless & Odourless & Odourless \\
\hline Taste & Tasteless & Tasteless & Tasteless & Tasteless & Tasteless & Tasteless \\
\hline Temp. & 25 & 26 & 26 & 25.5 & 26 & 26 \\
\hline Turbidity & 0.1 & 0.1 & 0.1 & 0.1 & 0.1 & 0.33 \\
\hline conductivity & 0.26 & 0.33 & 0.61 & 0 & 0.2 & 0.50 \\
\hline $\begin{array}{l}\text { Total suspended } \\
\text { solid }\end{array}$ & 1 & 0 & 0 & & 0 \\
\end{tabular}




\section{Chemical Analysis}

\begin{tabular}{|l|l|l|l|l|l|l|}
\hline & WS1 & WS2 & WS3 & WS4 & WS5 & WS6 \\
\hline Phenolphthalein & 0 & 0 & 0 & 0 & 0 & 0 \\
\hline Alkalinity & 0 & 0 & 0 & 0 & 0 & 0 \\
\hline Total Hardness & 36.04 & 36.64 & 28.63 & 34.03 & 32.03 & 28.03 \\
\hline Chloride Test & 42.55 & 49.64 & 21.28 & 42.55 & 35.46 & 21.28 \\
\hline Oxidizable Test & Pink & Pink & Wine & Wine & Pink & Pink \\
\hline Solid Test & 74.21 & 60.07 & 55.56 & 59.54 & 71.45 & 70.65 \\
\hline Total acidity & 17 & 29 & 22 & 17 & 41 & 20 \\
\hline Nitrates & 37.9 & 9 & 32 & 16.1 & 6.2 & 5.3 \\
\hline Phosphate & 1.43 & 1.25 & 0.41 & 1.87 & 0.68 & 3.6 \\
\hline Sulphate & 10 & 7 & 30 & 60 & 20 & 15 \\
\hline Disolved Oxygen & 10.89 & 7.55 & 8.34 & 9.69 & 8.93 & 1.9 \\
\hline
\end{tabular}

Microbial Analysis

\begin{tabular}{|l|l|l|l|l|l|}
\hline WS1 & WS2 & WS3 & WS4 & WS5 & WS6 \\
\hline No & No & No & No & No & No \\
Growth & Growth & Growth & Growth & Growth & Growth \\
\hline
\end{tabular}

\section{Results For Underground Sources}

\section{Physical Test}

\begin{tabular}{|l|l|l|l|l|l|l|}
\hline & UDW1 & UDW2 & UDW3 & UDW4 & UDW5 & UDW6 \\
\hline $\begin{array}{l}\text { Appearance } \\
\text { colour) }\end{array}$ & Colourless & Colourless & Cloudy & Colourless & Colourless & Cloudy \\
\hline Odour & Odourless & Odourless & Odourless & Odourless & Odourless & Odourless \\
\hline Ph & 4.2 & 5.6 & 3.8 & 3.6 & 4.6 & 8.0 \\
\hline Turbidity & 0.8 & 1.9 & 2.0 & 3.8 & 0 & 2.0 \\
\hline TSS & 3 & 1 & 0 & 1.67 & 2.6 & 0.5 \\
\hline Conductivity & 3.52 & 2.11 & 2.08 & & 3.60 \\
\hline
\end{tabular}

\section{Chemical Test}

\begin{tabular}{|l|l|l|l|l|l|l|}
\hline Total Alkalinity & 65 & 30 & 45 & 25 & 26 & 30 \\
\hline Total Acidity & 75 & 38 & 50 & 45 & 56 & \\
\hline Chloride & 80 & 91 & 75 & 68 & 20 & \\
\hline Nitrates & 10.5 & 30 & 2.1 & 2.9 & 62 & 30 \\
\hline Phosphates & 0.3 & 78 & 110 & 2.8 & 65 & 3.0 \\
\hline Total hardness & 76 & 6 & 8 & 19 & 60 & 70 \\
\hline Sulphates & 13 & 8.7 & 9.0 & 10.5 & 3.5 & 10.2 \\
\hline D.O & 8.0 & & & 95 \\
\hline
\end{tabular}

\section{Physical Test}

\section{WHO STANDARD}

Temperature--------- $35-40^{\circ} \mathrm{C}$

PH -

Turbidity (mg/l) -----------5

Conductivity ------------1.0

Total suspended solid-------30

\section{Chemical Test}

Total Acidity -----------NS

Total Alkalinity ---------200

Total Hardness (mg/l) ---100

Chloride (mg/l) ---------250

Nitrates (mg/l) ----------10

Phosphates (mg/l) ------5

Sulphates (mg/l) -----250

Dissolved oxygen (mg/l) (min) -----2.0

Magnesium ------150 (0.02) max. Permitted

Sodium-------------200

Pottasium ----------- $<20$

Zinc -------------1.5

Maganese ---------0.5

Iron ----------------0.03

Nickel --------------0.02 
Silver --------------NS
Lead --------------0.015

\section{Discussion}

All physical analysis tests on the sample recorded positively and adhere to set standards.

In chemical analysis, the chloride test values of all samples were below the maximum standard $250 \mathrm{mg} / 1$, which confirms that the samples contain chlorine in normal proportion for the disinfections of bacteria in the samples.

The presences of chlorine in the sample neglect the presence of bacteria when the samples were cultured except the temperature and the nitrate contents which do not conform with WHO standards. The temperature of all the sachet samples falls below the required standard temperature of $35-40{ }^{\circ} \mathrm{C}$ which can allow the growth of pathogenic organism. Excessive nitrate in samples 1,3 and 4 can be harmful to life, Nitrate breakdown to become Nitrite which react with Heamoglobin in human blood to produce methemoglobin that limits the ability of red blood cells.

For underground sources samples 3 and 6 was cloudy probably due to the presence of metallic contaminants around the two sources. The PH of all samples ranges from 3.6-5.6 which is acidic except sample 6 with PH 8.0. This may be due to presence of nitrate in the source. Dissolve oxygen, conductivity and Nitrate test in all the sources were higher than the WHO standard and only sample C have a higher concentration in total hardness which indicates heavy presence of calcium or magnesium ions in the sample.

\section{Conclusion/Recommendation}

\section{Conclusion}

In conclusion, the result shows that the water sample used are good for human consumption except sample WS1, WS3 and WS4 of the sachet water samples with higher nitrate values.

\section{Recommendation}

It is therefore recommended that attention should be shifted not only to pure water consumed by people but also to the sources of water used in the production of pure water. The water should be analyzed and monitor properly to avoid fake duplicate of the water used and to investigate different product of pure water properly because health is wealth.

\section{Reference}

[1]. A text book of microbiology by R.C Dubey, D.Kmaheswari

[2]. Brock biology of microorganism by Madigametall $12^{\text {th }}$ Edition

[3]. Chemistry and introduction to general, organic and biological chemistry by Karen .C Timberlake $10^{\text {th }}$ edition

[4]. Chemistry by Raymond chang $8^{\text {th }}$ edition

[5]. Fundamental food microbiology by Bibek ray and Arum Bhunia $4^{\text {th }}$ edition

[6]. Fundamental of chemistry by David E Goldberg $4^{\text {th }}$ edition

[7]. General chemistry by Wendell H. Slabaughetall $3^{\text {rd }}$ edition

[8]. Microbiology a human perspective by Nester Anderson $5^{\text {th }}$ edition

[9]. Microbiology and introduction by Tortora Funke, Case $9^{\text {th }}$ edition

[10]. New school chemistry by Osei Yaw Ababio $5^{\text {th }}$ edition

[11]. Principles of modern chemistry by Oxtobis Gillis Campion $6^{\text {th }}$ edition

[12]. Wikipedia

[13]. www.lenntech.com 